\title{
The Business Intelligence Group: Towards Collaborative Research In A Management Information Systems Curriculum
}

David Olsen, Utah State University, USA

Vance Cooney, Eastern Washington University, USA

\begin{abstract}
This paper introduces an extension of an approach referred to as the Research Group model, an award winning pedagogical methodology based on the premise that when undergraduate students engage in academic research in close consultation with their professors that their marketable skills are greatly enhanced and that the institutions involved benefit greatly as well. The history of the Research Group concept is detailed, the incentive structure that facilitates faculty buy in is explained and the extension to the general model that defines the Business Intelligence (BI) Group is described. The paper outlines several exemplar projects that have resulted from the approach.
\end{abstract}

Keywords: Management Information Systems (MIS); Business Intelligence (BI); Data Quality; Professional Research Organization; Mentoring; Program Development

\section{INTRODUCTION}

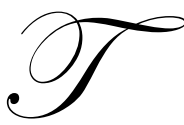

his article introduces a model pedagogy called the Business Intelligence (BI) Group as an innovative approach to collaborative research between students and faculty in management information systems program. The basic tenet underlying the BI Group concept is that 1) undergraduate student participation in research projects has a salutary influence on both academic performance and career advancement upon graduation and 2) the student's research experience is enhanced when collaboration provides one-on-one with their professors; mentoring that is not typical in traditional undergraduate student research models. The BI Group concept developed along the lines of a scholarly think tank or professional research organization; e.g., a law practice with senior and junior partners, etc.

The Research Group model posits that students are able to acquire a more in-depth knowledge of the research process and its application because both the faculty mentor and student are involved in the same project and the mentor and student are both more heavily invested than in traditional assigned research - the faculty because quality research is more likely to result in publication and the student because such research may more likely result in a job.

Student career enhancement facilitated by research collaboration with faculty mentors results because students become more valuable potential participants in analytically-driven organizations. Regarding the talent needed in such analytically-driven organizations, Harris, Craig, and Egan (2009) outline four areas of skills emphasis: 1) technical and quantitative, 2) business knowledge and design, 3) relationship and consulting, and 4) coaching and staff development. To these, we add a fifth skill in our BI Group, which is data quality, storage and manipulation and includes focused mentoring in Business Intelligence which we argue is the new frontier in organizations in terms of ROI. Our mentoring includes all five of these areas with a special emphasis on BI.

Many of our students conduct research in analytical applications applied to industry specifics. Examples include applications in financial services, such as program trading and fraud detection; in healthcare, such as disease management and public health outcomes as mandated by the Hi-Tech act of the 2009's meaningful use clause and in 
hospitality, such as customer loyalty and pricing. Inevitably, in doing such research, students have a competitive advantage in either their chosen career field or in acceptance to graduate school.

To better understand the nature and scope of the BI Group model, the following sections provide background on the importance of student research experiences, the administrative structure of the program, and the outcomes from collaborative research. We conclude with guidelines for the successful implementation of a $B I$ Group.

\section{BACKGROUND}

The first question that might be asked is whether or not participation in student/faculty research adds value to the educational experience, in general, and to the student educational experience, in particular. In other words, why have a BI Group in the first place? To adequately respond to these questions, evidence needs to be provided that student participation in research enhances the educational experience and that business intelligence is an important research domain.

With regard to the first issue, involving students in research experiences clearly provides benefits to the institution (Gates et al., 1999; and Schneider, 2004). For example, Schneider (2004) maintains that research programs can "result in more successful and competitive alumni, serve as a selling point for recruiting freshman, provide positive publicity, lead to greater overall productivity, and impart a more mature learning atmosphere" (p. 90). In this regard, Clotfelder (2001) studied factors that contribute to alumni giving. He found that higher levels of contribution were associated with having had a mentor in college.

As to student educational experience, there is equal clarity in the evidence. Elgren and Hensel (2006), for example, note that "Inviting students to invest intellectually in a project gives them the opportunity to help shape its direction, exert some of their own creativity, and experience the joy of intellectual 'ownership' of the products resulting from the effort" (p. 6).

With regard to the importance of BI, let us first more formally define the term. BI is a methodology that uses hardware, software and analytical reasoning and tools to acquire and build a better view of the data and information within an organization. By organizing internal and external information into a data warehouse (the modal vehicle for conducting BI analysis) and analyzing this formation with predictive models, one can provide better information to help the organization make better decisions, which in turn creates competitive advantage. Intuitively, this would support an increase in interest in BI, and our research backs that up. For example, research has shown an increasing demand for graduates who understand how businesses operate and have both technical and quantitative competence to effectively analyze large volumes of business data (Caputo et al., 2006, and Teradata survey, 2009).

So the decision to develop a BI Group was not a random event, nor was it based merely on the individual interests of faculty (although faculty resources and expertise always play a role in program development). Instead, the faculty identified business intelligence as an increasingly important component of the MIS portfolio. Therefore we have a model to engage and benefit student and faculty and a rationale to place emphasis on BI. The next step is to operationalize our concept.

While our approach takes heed of all four areas of skills identified by Harris, Craig, and Egan (2009), this paper deals primarily with our fifth skill area - BI. Because of the high value business intelligence provides to an organization, companies, such as SAP, IBM, Oracle, SAS, Accenture and numerous other consultants and vendors, have all established a significant presence in the area. Although each of these organizations has their own and spin on what constitutes BI, they all have many commonalities, most of which focus on finding trends in existing data that provide information to business decision makers throughout the organization.

The demand for students trained in aspects of business intelligence is further supported by recent survey research. Sullivan (2008), for example, reported CIO rankings of critical Information Technology areas and found that the top two items are: 1) data storage issues and 2) the need to make sense of the mass of collected data. 
It appears, therefore, that the development of a program that addresses the aforementioned issues in the referenced manner is a worthwhile endeavor and presents the development of the BI Group in the Jon M. Huntsman School of Business as an exemplar of the marriage of topic and approach. And, while it is understood that the most common, and perhaps efficient, means of addressing these issues is through coursework development, we maintain that extra-curricular participation in research collaborations can provide students with an additional competitive advantage, particularly in today's increasingly complex and competitive work environment.

If we accept the notion that research experiences benefit the student and the educational institution, the next issue to address is the scope of research experiences in colleges and school of business. Unfortunately, the evidence is not entirely encouraging. Bartkus (2007), for example, notes that:

While the number of bachelor's degrees conferred in the United States during 2004-05 was approximately 22 percent of the total (U.S. Department of Education 2006), the number of business projects presented at the 2007 National Conference on Undergraduate Research was only 2.3 percent. Furthermore, of the 60 posters presented at the 2006 Posters on the Hill session, not a single one was from the area of business. (6)

He also notes that business faculty participation in relevant professional organizations is also underrepresented. In particular, he notes that business faculty membership in the Council of Undergraduate Research is only about .3 percent of the total. Perhaps this is due to the fact that the Council does not even have a Business division within the organization. Still, within the Council's division of social science, the area that appears most directly related to business, Bartkus (2007) reports that the representation is still less than 5 percent.

It would appear reasonable to infer that if the majority of MIS programs are located in colleges and schools of business, the level of participation by MIS students and faculty is even lower.

The challenge, therefore, is how to develop a program that would both effectively and efficiently address this deficiency. Such a program would need to be effective to the extent that it provides real value to both the student and the educational unit. Additionally, it would need to be efficient in the sense that it had a meaningful value proposition; that is, its benefits outweigh the costs. An inefficient program would simply drain needed resources from other areas.

To help achieve the dual objectives of effectiveness and efficiency, the BI Group was patterned after the success of the more general Research Group model that was developed a few years earlier in the same school of business. As a multi-disciplinary business program, the Research Group provided was both highly credentialed and bona fide. In 2008, it was the recipient of the Exemplary Models Award from the American Association of University Administrators. This award "recognizes outstanding examples of college/university leadership that demonstrate creative solutions to common problems in higher education" (http://www.aaua.org/assemblies/2010/awards_call.htm). Additionally, the Research Group had a great deal of success in publishing with students and placing them in prestigious graduate schools.

It made sense, therefore, to build on this success with the development of the BI Group. The result is a more specialized research group that attracts faculty by providing relevant outcomes that are transparent to their careers; in essence, faculty participating in the BI Group (hereafter referred to as the BI Group) are able to demonstrate contributions in the three major areas of responsibility - service, teaching, and research.

For example, faculty participating in the BI Group receive credit for service to the program through their participation in the planning, implementation, and administration of the group activities. In other words, besides working with students, participating faculty are responsible for coordinating seminars, scheduling events, and generally ensuring that the program operates efficiently and effectively.

Faculty also receive teaching credit for their participation. In this regard, we have found that the mentoring process is now considered a valued teaching activity by university administration as it helps ensure student success in graduate school and their chosen careers. 
Finally, faculty receive credit for research when the results are published. The BI Group follows the tradition set by the Research Group in that it is expected that all projects will eventually be published or presented in an appropriate forum. This objective helps ensure that the research is both relevant and rigorous in its application. Since 2004, the two programs have produced over two dozen collaborative research papers in either a proceedings or journal. Many of these were student/faculty collaborations were in the area of Management Information Systems.

\section{ADMINISTRATIVE STRUCTURE}

The BI Group has an administrative structure that consists of a director, managing partners, corporate partners, and associates. The director coordinates research activities of the BI Group and serves as a liaison to the business community and to administrators in the college and university. Managing partners are MIS scholars and are responsible for coordinating projects and mentoring students. They also serve on the advisory board for the $B I$ Group. Corporate partners are individuals within organizations that are external to the university but share a common interest in business intelligence. Through this partnering, the university builds a better crosswalk to the professional community. They are primarily involved in providing guidance and feedback with regard to research issues that are important to the discipline.

Associates are student researchers. They participate in the research process in a manner similar to an internship or apprenticeship. Students are encouraged to list their involvement on their resumes under professional development.

In this way, the BI Group presents itself as a professional organization that builds a "crosswalk" to the business community by conducting research that is consistent with the real world. In all cases, research in the $B I$ Group is vetted by faculty to ensure that it is rigorous in its application of sound business intelligence principles and relevant in its consideration for how that information can be used to meet the challenges of business organizations.

It is also important to note that it might be tempting to refer to the BI Group as an Undergraduate Research Program. After all, the major impetus for the program is to provide students with a meaningful undergraduate research experience. We would argue, however, that there are important differences. In particular, traditional undergraduate research programs typically require the research to be student-driven with only advisory council from the mentor.

While the BI Group believes that traditional models provide important experiences, it also believes that students gain added value by participating in a program that is research driven and treats the student and faculty member as collaborating professionals who work together to solve a research problem. To be sure, there remains a mentoring relationship, but faculty involvement in the project and in the mentoring process are what fundamentally distinguishes a traditional undergraduate research experience from one in the BI Group. In this way, it is intended that the structure of the BI Group will provide an experience that better reflects a real-world, professional experience.

\section{SUGGESTED GUIDELINES FOR PROGRAM DEVELOPMENT}

To help facilitate the development of a BI Group, we present five suggested guidelines that will be helpful in meeting challenges of implementing and administering the program:

Guideline 1: Foster Institutional Support. It is doubtful that any program can ultimately be successful without institutional support and commitment. Evidence of commitment can come in a variety of forms, but should always include incentives for participation, both monetary and non-monetary. For example, Utah State University provides an award for "Outstanding Undergraduate Research Mentor of the Year" with a monetary stipend and paid membership to the Council on Undergraduate Research. 
Guideline 2: Recruit Appropriate Faculty. In this regard, it makes sense to recruit senior faculty with established research records. Senior faculty tend to have a more acute understanding of the research process, particularly as it relates to mentoring. Most importantly, they are unburdened by the tenure and promotion process. These faculty can also serve to mentor junior faculty in undergraduate research, thereby helping to enhance their promotion and tenure portfolio.

Guideline 3: Recruit Qualified Students. Typically, it makes sense that students should be academically qualified. Without adequate academic qualifications, the task of mentoring a student can become quite burdensome. However, we have also found that that highly motivated, but less academically qualified students can perform quite well in the program. The lesson is that multiple criteria should be considered when qualifying students.

Guideline 4: Cultivate college advocates. We found that it is important to cultivate advocates for the program people who will serve as "cheerleaders" for the program. The most likely advocates are department heads and the associate dean responsible for student and faculty development. At the university level, the vice-president of research should also be consulted for guidance on developing the program.

Guideline 5: Keep a file of project ideas. By identifying meaningful and doable projects beforehand, they can be referenced as new students enter the program. By regularly updating the list, you help ensure that project ideas are not developed at the spur of the moment. More importantly, having a portfolio of projects allows the ideas to be more carefully vetted for suitability.

\section{CURRENT AND PAST PROJECTS}

To better understand the nature and scope of research currently being conducted in the BI Group, the following examples are presented. We also include brief abstracts of research that has been published.

Current projects relate to improvements in pedagogy for business intelligence. The first project involves the creation of business intelligence modules in the undergraduate database class using Microsoft SQL Server Analysis Services 2008 to deploy cubes and show BI as a proof of concept. These modules are intended to demonstrate some technical aspects of BI; but more importantly, it shows how quickly large quantities of data can be analyzed for improved decision-making.

The second project explores the feasibility of replacing a business statistics course with a business intelligence course that emphasizes business statistics from a data analysis standpoint rather than the traditional statistics approach. The rationale is that one of the major challenges organizations face today is that there is an abundance of data and they need to know how to utilize, manage, and analyze it for improved business decision making purposes. A statistics course that centers on the principles of business intelligence could provide students with these competencies.

The BI Group has also published several articles. In the first article by Mills, Olsen and Powell (2009), the researchers analyzed data from five different types of EBay auctions to analyze the effect of the Power Seller rating to the final auction price. The results confirmed those from prior studies that showed a positive relationship between final selling price and the Power Seller rating for goods that are readily available, or goods with strong demand. However, this study also showed an unusual result - for goods that have overwhelming demand, the final selling price is inversely correlated to the Power Seller ranking. The authors postulate that goods that have very high bidding prices with numerous bidders are subject to "irrational exuberance".

In a second study by Olsen, Cooney, Marshall, and Swart (2005), the researchers demonstrated the process of integrating the extensible markup language (XML) into an industrial database system. They provided three scalable methods of importing XML from web applications into a corporate data warehouse to be used for analytics and business intelligence. The research also demonstrated three scalable methods for generating web usable XML 
data from existing tables using the relational database structure. These methods were tried and tested in the corporate environment, as well in MIS department projects, and were ultimately successful.

\section{CONCLUSIONS}

The purpose of this paper was to introduce an innovative program that seeks to provide a meaningful research experience for students. Because the BI Group is modeled after a professional research organization, the level of mentoring is thought to be significantly higher than would otherwise be provided for in a traditional undergraduate research program. The result is higher quality and better value for the student.

With that said, the effectiveness of the program comes at a cost; in essence, collaborative research programs require a greater time commitment from faculty. Additionally, while the collaborations often result in research publications, it is less common that students have the capability to contribute to projects that are targeted to high-end journals. Finally, faculty must be willing to share their research with students. In many cases, the idea and initial project set-up is developed by the faculty mentor. This is by design as it increases efficiency and ensures a meaningful project. Nonetheless, the faculty member needs to be willing to allow others to share in the contribution. Our philosophy on this issue is that it is perhaps not all that different from many other collaborative projects involving multiple faculty. Hence, we view this as part of the professional development process and a natural consequence of a productive and cohesive learning environment.

\section{AUTHOR INFORMATION}

David Olsen received his Ph.D. in Management Information Systems from the University of Arizona in 1993 and taught at The University of Akron accounting department in accounting information systems for five years. Dr. Olsen joined the MIS department at Utah State University in 1998 and teaches primarily in the database area. His research interests are primarily in database systems and business intelligence. His research has been published in journals such as Communications of the ACM and the Journal of Database Management. Dr. Olsen is most pleased with the teaching awards he has received. E-mail: david.olsen@usu.edu

Vance Cooney received his Ph.D. in Management Information Systems from the University of Arizona in 2001 and taught at Xavier University in Cincinnati, Ohio from 1996 until 1999. Since 1999 Dr. Cooney has taught at Eastern Washington University. His research and teaching interests are information systems and, in particular database systems. He recently helped launch the Health Informatics program at Eastern. E-mail: vcooney@ewu.edu

\section{REFERENCES}

1. Bartkus, K. (2007). Fostering student/faculty collaborations through the Research Group Model: An application to colleges and schools of business," CUR Quarterly, 28(2), 6-10.

2. Caputo, D. J., Kovacs, P. and Turchek, J. C. (2006) "Defining the Essential Skill and Functional Areas of Study in Information Technology as Measured by a Survey of Field Professionals", Information Systems Education Journal, Vol.4, (6)

3. Clotfeldler, Charles T. (2001), "Who Are the Alumni Donors? Giving by Two Generations from Selective Colleges," Nonprofit Management \& Leadership, 12(2) 119-138.

4. Harris, Jeannen G., Elizabeth Craig. And Henry Egan, "How to create a Talent-Powered Anlytical Organization," research report, Accenture Institute for High Performance, 2009.

5. Elgren T, Hensel N. Undergraduate research experiences: Synergies between scholarship and teaching. Peer Review. 2006(8):409-414.

6. Gates A, Teller P, Bernat, A, Delgado, N, Della-Piana C. Expanding participation in undergraduate research using the affinity group model. J Eng Educ. 1999(88):409-414.

7. Robert J Mills, David Olsen, Myles Powell "Examining intervening variables of the EC Consumer Behavior Model: The PowerSellerTM and Phenomenon Search Products", Vol. 13 No. 4, December, 1 2009, pg. 45-50, Review of Business Information System.

8. David Olsen, Vance Cooney, Bryan Marshall, Richard Swart, (Fall 2005), "Towards Full Integration of XML and Advanced Database Concepts," Review of Business Information Systems, vol. 9 no. 4. 
9. Schneider LE. Undergraduate research: Responsibility of a research university. J of Water Resour Plann and Manag. 2004(130):89-92.

10. Sullivan, T. (2008) "Top IT Spending Priorities in an Economic Recession", CIO, http://www.cio.com/article/464513/Top_IT_Spending_Priorities_in_an_Economic_Recession, (accessed Aug 31, 2010)

11. Teradata University Network (2009) "The State of Business Intelligence in Academia", http://www2.commerce.virginia.edu/bicongress/images/BI\%20in\%20Academia\%202009.pdf, (accessed Aug 31, 2010)

12. U.S. Department of Education, National Center for Education Statistics. Digest of Education Statistics. 2006(NCES 2007-017), Ch 3. 
International Journal of Management \& Information Systems - Fourth Quarter $2011 \quad$ Volume 15, Number 4 NOTES 